\title{
Development of an optimal process for friction stir welding based on GA-RSM hybrid algorithm
}

\author{
Nabi Mehri Khansari \\ University of Tebran, Iran \\ nabi_mebri@ut.ac.ir \\ Filippo Berto \\ Norwegian university of science and technology (NTNU), Norway \\ filippo.berto@ntnu.no
}

Namdar Karimi

Babol University of Technology, Iran

namdarkarimi@gmail.com

\author{
S.M.N. Ghoreishi, Mahdi Fakoor \\ University of Tebran, Iran \\ mfakoor@ut.ac.ir,navid_ghoreishi@yahoo.com
}

\author{
Mozhgan Mokari \\ Sharif University of Technology, Iran \\ mozhgan.mokari@yahoo.com
}

\begin{abstract}
Performance of Friction Stir Welding (FSW) as a solid-state process is approved in several engineering applications, especially aluminum industries. Identification of mechanical behavior of the associated welded zone is necessary due to these extensive applications of FSW. In this study, considering the effect of rotational and forward speed of welding tool on the mechanical properties of welded region, a hybrid optimization method based on combination of Genetic Algorithm (GA) and Response Surface Method (RSM) named here as GA-RSM is proposed to achieve maximum tensile and ultimate strength. The results of GA-RSM are validated by per-forming necessary experimental tests on two wide-used 2024 and 5050 aluminum alloys. The results show that GA-RSM could be an effective approach to achieve optimized process for FSW with minimum cost.
\end{abstract}

KEYWORDS. Friction Stir Welding (FSW); Optimized mechanical properties; Genetic Algorithm (GA); Response Surface Methodology (RSM).

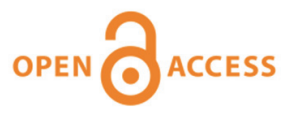

Citation: Khansari, N.M., N., Berto, F., Karimi, N., Ghoreishi, S.M.N., Fakoor, M., Mokari, M., Development of an optimal process for friction stir welding based on GARSM hybrid algorithm, Frattura ed Integrità Strutturale, 44 (2018) 106-122.

Received: 16.02 .2018

Accepted: 02.03.2018

Published: 01.04.2018

Copyright: (C) 2018 This is an open access article under the terms of the CC-BY 4.0, which permits unrestricted use, distribution, and reproduction in any medium, provided the original author and source are credited. 


\section{INTRODUCTION}

S pecial and attractive properties of Aluminum alloys such as high strength to weight ratio, acceptable toughness and corrosion resistance has resulted in the impressive use of aluminum in various industries. Considering different types of materials, which may employed for construction of a structure, several researches have been done to investigate the joining of aluminum alloys to the similar alloys or the other materials. Some selected researches are reviewed in the following.

Habibnia et al. investigated the effects of rotation and forward speed of tool on the friction stir welding of $1100 \mathrm{Al}$ alloy to carbon steel [1]. Uzun et al. investigated the joining of dissimilar Al 6013-T4 alloy and X5CrNi18-10 stainless steel using fric-tion stir welding technique [2]. They also reported a good correlation between the hardness distribution and the welding zones of $\mathrm{Al}$ 6013-T4 alloy and X5CrNi18-10 stainless steel joint. Lee et al. studied the reaction layers of friction stir welded joints made from austenitic stainless steel and $\mathrm{Al}$ alloy consisted of mixed layers of elongated, ultra-fine grains and the intermetallic compound layer [3]. Zhu and Chao, proposed a numerical simulation of transient temperature and residual stresses in friction stir welding of 304L stainless steel [4]. Furthermore, effects of welding fusion, joint strength and welding microstructure were investigated and reported, experimentally [5-7]. Moreover, the reports accent more difficulties in welding process of dissimilar alloys toward similar ones [1]. The main reason of the problem is due to the differences between their melting points, mechanical properties and welding method. On the other hand, in dissimilar welding process, the material with a lower melting point will melt quickly whereas; the other one remains solid and undesirable defects may appear in the welding zone. Indeed, definition of an optimized method for dissimilar alloys due to difficulties is necessary.

However, it has been proven practically that FSW, as a solid-state method is able to eliminate the formation of the intermetallic phase and to form uniform solid joints [8-9]. In addition, friction stir welding is a recent technique that utilizes a non-consumable rotating welding tool to generate frictional heat and plastic deformation at the welding location [10]. In FSW procedure, the desired plates are aligned with each other and clamped using fixtures. The tool rotates at high speed and moves along the weld centerline to generate connection between the work pieces. Sharma has given a convenient overview of friction stir welding of aluminum to copper [11].

In this subject, three different zones can be observed in welded zones, including, Heat Affected Zone (HAZ), Thermo Mechanically Affected Zone (TMAZ) and Fric-tion Stir Processed (FSP) zone [1]. The formation of the above regions is affected by the material flow behavior under the action of the mentioned rotating non-consumable tool. FSW has been studied from microstructural point of view in sever-al researches $[12,13]$.

In FSW method, it is essential to have a complete control over the relevant process to maximize the mechanical properties of the joint and to obtain desired strength.

It is very important to select and control the welding process parameters for obtaining the maximum strength. Various prediction methods can be employed to define the desired output variables. The relationship between FSW input parameters and output variables could be specified through developing mathematical models. In this regard, artificial neural network [14, 15], Taguchi optimization technique [16, 17], genetic algorithm, fuzzy logic, and other optimization methods were applied $[18,19]$. Kumar and Murugan employed FSW to maximize tensile strength and keep the mechanical properties in welding process of Aluminum matrix composites. In this study, key parameters in FSW such as tool rotational speed, welding speed and axial force are used to develop regression models for prediction of the ultimate tensile strength and percent elongation [20]. Qian et al. proposed an analytical approach for optimization of rotational and travel speed in FSW by trial and error [21]. Recently, the Response Surface Methodology (RSM) is introduced as a helpful approach in developing a suitable approximation for the true functional relationship be-tween the independent variables and the response variable that may characterize the nature of the joints. Sometimes, response surface methodology is combined with other optimization methods like computer aided artificial neural network for more efficiency [22, 23].

As it can be found from the above literature, although, different researches have been done on various topics of FSW but presentation of optimum parameters for welding tool needs further development. Therefore, in the present research, a hybrid optimization methodology is proposed based on combination of Genetic Algorithm (GA) and the Response Surface Methodology (RSM) named here as GA-RSM to approximate the optimal tool's rotational and forward speed in which maximum tensile strength could be achieved. Then, presented optimization method based on empirical data is executed to obtain maximum tensile and ultimate strength of the welded region. In this regard, experimental tests are performed on two applicable 2024 and 5050 aluminum alloys in proposed optimized speeds. 


\section{MATERIALS AND METHOD}

$\mathrm{F}$ riction Stir Welding (FSW) is a solid-state joining process that utilizes a third body tool to join two facing surfaces. Heat is generated between the tool and material that leads to a very soft region near the FSW tool. It then mechanically intermixes the two pieces of metal at the place of the joint, and then the softened metal due to the elevated temperature can be joined using mechanical pressure which is applied by the tool. Fig. 1 illustrates both the friction stir welding tool and the relevant procedure parameters.

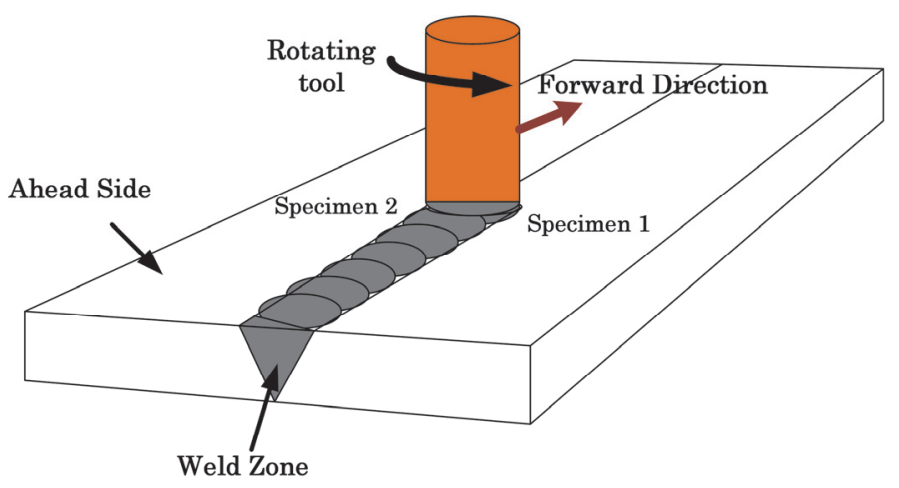

Figure 1: Friction stir welding process, schematically

In the present study, cold-rolled 2024 and 5050 aluminum alloy have been selected for friction stir welding process. Chemical composition of aluminum alloy is listed in Tab. $1[1,18]$.

\begin{tabular}{ccccccccccc}
\hline Elements & $\mathrm{Mg}$ & $\mathrm{Cu}$ & $\mathrm{V}$ & $\mathrm{Ni}$ & $\mathrm{Cr}$ & $\mathrm{MN}$ & $\mathrm{Si}$ & $\mathrm{Ti}$ & $\mathrm{Zn}$ & $\mathrm{Al}$ \\
$\mathrm{AA} \mathrm{5050}$ & 75.5 & 0.043 & 0.010 & $<0.005$ & 0.010 & 0.224 & 0.120 & 0.018 & $<0.008$ & others \\
$\mathrm{AA} \mathrm{2024}$ & 1.57 & 4.15 & 0.001 & $<0.005$ & 0.014 & 0.53 & 0.06 & 0.09 & 0.13 & $\approx 93.4$ \\
\hline
\end{tabular}

Table 1: Chemical composition of Aluminum Alloy 2024 [1, 18].

Furthermore, the sheets are cut in dimensions of $3 \times 100 \times 150 \mathrm{~mm}$ and are fixed in preferred fixture. In addition, HSS and H13 have been utilized as welding tool. The chemical composition of FSW's tools represents in Tab. 2.

\begin{tabular}{lccccccccccc}
\hline Elements & $\mathrm{Fe}$ & $\mathrm{Si}$ & $\mathrm{MN}$ & $\mathrm{Cu}$ & $\mathrm{C}$ & $\mathrm{Ni}$ & $\mathrm{Cr}$ & $\mathrm{V}$ & $\mathrm{Co}$ & $\mathrm{W}$ \\
Hss Tool & 75.5 & 0.32 & 0.25 & 0.109 & 0.88 & 0.163 & 3.57 & 1.90 & 0.09 & 7.32 \\
H13 Tool & 91.7 & 1.07 & 0.47 & 0.06 & 0.30 & 0.04 & 4.37 & 0.95 & 0.45 & 0.08 \\
\hline
\end{tabular}

Table 2: Chemical composition of HSS and H13 tools [18].
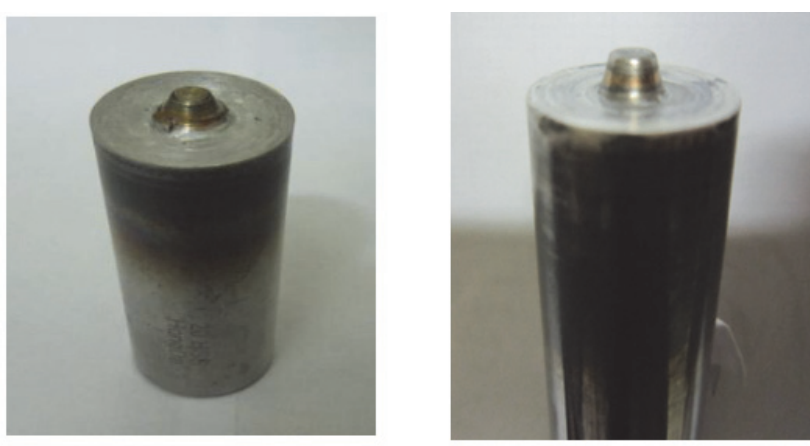

Figure 2: HSS tool's spin used in the present research 
The tool consists of $7.2 \mathrm{~mm}$ pins and $20 \mathrm{~mm}$ shoulder to transfer materials to the welding region. In addition, the shoulder set at angle of $6^{\circ}$ to create convenience force whenever it passes through the weld-line. Fig. 2 shows the tool that is employed for both 2024 and AA5050. Welding process was performed in different rotational and forward speed.

\section{WELDING OPTIMIZATION ALGORITHM}

\section{Genetic algorithm $(G A)$}

G enetic algorithm is an iterative search procedure for optimization of an objective function, which describes the mechanics of natural genetics and natural selection [24]. Although, GA has apparently simple method in computation, it is powerful in search. On the other hand, it does not need any specific properties of the problem. The application of GA needs to generate a population among candidate solutions to approximate the ideal populations, gradually. This procedure continues until satisfaction of specified criterion. In this regard, each chromosome of a population should be evaluated and compared with other one to achieve a better objective function. The individuals, who lead to a better objective function, have a greater chance for selection and pass their genes to next population. Several stopping criteria are available to check in this step.

\section{Response Surface Method (RSM)}

The Response Surface Method (RSM) is employed to obtain an approximation for response function in terms of independent variables [25]. The most practical applications of RSM are in the empirical tests, particularly in situations where several input variables potentially influence in results. RSM is consisted of mathematical and statistical techniques that are based on the fit of the best empirical models on the extracted exploratory data from experimental tests. Common form of the response is usually written as [25]:

$$
y=F\left(x_{1}, x_{2}, \ldots, x_{n}\right)+\varepsilon
$$

where $\mathrm{y}$ is the estimated response, $\mathrm{x}_{\mathrm{i}}$ are independent variables, and $\varepsilon$ is an error term. The function $\mathrm{F}$ is usually selected to be a polynomial. For a quadratic polynomial, $\mathrm{F}$ is written as [25]:

$$
F=\beta_{0}+\sum_{i=1}^{N} \beta_{i} x_{i}+\sum_{1 \leq i \leq j}^{N} \beta_{i j} x_{i} x_{j}
$$

where $\beta$ represents as unknown coefficients and calculated by a linear multiple regressions based on the least square methods. The linear multiple regression models are rewritten in matrix form as follows [25]:

$$
\mathrm{Y}=\mathrm{X} \beta+\varepsilon
$$

in which, $\mathrm{Y}, \mathrm{X}, \beta$ and $\varepsilon$ are defined as:

$$
\mathrm{Y}=\left\{\begin{array}{c}
y_{1} \\
y_{2} \\
\vdots \\
y_{n}
\end{array}\right\}, \quad \mathrm{X}=\left[\begin{array}{ccccc}
1 & x_{11} & x_{12} & \cdots & x_{1 k} \\
1 & x_{21} & x_{22} & \cdots & x_{2 k} \\
\vdots & \vdots & \vdots & \ddots & \vdots \\
1 & x_{n 1} & x_{n 2} & \cdots & x_{n k}
\end{array}\right], \beta=\left\{\begin{array}{c}
\beta_{0} \\
\beta_{1} \\
\vdots \\
\beta_{k}
\end{array}\right\}, \quad \text { and } \quad \varepsilon=\left\{\begin{array}{c}
\varepsilon_{1} \\
\varepsilon_{2} \\
\vdots \\
\varepsilon_{n}
\end{array}\right\}
$$

In general, $\mathrm{Y}$ is a $n \times 1$ vector of the observations, $\mathrm{X}$ is a $n \times k$ model matrix including the levels of the independent variables expanded to model form, $\beta$ is a $k \times 1$ vector of the regression coefficients, and $\varepsilon$ is a $n \times 1$ vector of random errors. The unbiased estimator $b$ of the coefficient vector $\beta$ is obtained using the least square error method as follows [26]:

$$
\mathrm{b}=\left(\mathrm{X}^{T} \mathrm{X}\right)^{-1} \mathrm{X}^{T} \mathrm{Y}
$$

in which, the variance-covariance b matrix could be rephrased as function of error [26]: 


$$
\operatorname{Cov}\left(b_{i}, b_{j}\right)=C_{i j}=\sigma^{2}\left(\mathrm{X}^{T} \mathrm{X}\right)^{-1}
$$

where $\sigma$ is the error of $\mathrm{Y}$ and can be obtained as follows:

$$
\sigma^{2}=\frac{\mathrm{Y}^{T} \mathrm{Y}-\mathrm{b}^{T} \mathrm{X}^{T} \mathrm{Y}}{n-k-1}
$$

The adjusted coefficient of multiple determinations $R^{2}$ (R-square-adjusted) is used to evaluate the performance of the approximation of the response surface and can be defined as [26]:

$$
\mathrm{R}^{2}=1-\frac{\mathrm{Y}^{T} \mathrm{Y}-\mathrm{b}^{T} \mathrm{X}^{T} \mathrm{Y} /(n-k-1)}{S_{y y} /(n-1)}
$$

in which, $\mathrm{S}_{\mathrm{yy}}$ is proposed as follows [26]:

$$
S_{y y}=\mathrm{Y}^{T} \mathrm{Y}-\left(\sum_{i=1}^{n} y_{i}\right)^{2} / n
$$

Each coefficient of the response surface can be tested using the t-statistic. The statistic of the coefficient $b_{j}$ is [26]:

$$
t_{0}=\frac{b_{j}}{\sqrt{\sigma^{2} C_{j j}}}
$$

where $C_{i j}$ is the element of number $j$ of the variance-covariance matrix of Eq. (6). In the present research, coefficient $R^{2}$ (Eq. 8) has been calculated for validation of model's goodness.

Hybrid optimization algorithm based on combination of Genetic Algorithm and the Response Surface Methodology (GA-RSM) In the present study, a hybrid optimization methodology based on both Genetic Algorithm (GA) and the Response Surface Methodology (RSM) named here as GA-RSM is proposed to obtain the optimum solution for a defined objective function. In this regards, in the genetic algorithm process, objective functions in each evaluation are calculated by response surface. Fig. 3 illustrates flowchart of the developed hybrid optimization algorithm based on combination of Genetic Algorithm and the Response Surface Methodology (i.e. GA-RSM).

According to the proposed flowchart, the optimization algorithm starts by creating a random initial population. Then, objective functions for each individual are evaluated from response surface, directly. Then, according to the obtained objective functions, algorithm ranks of each individual part is evaluated. After that, a stochastic method is adopted for selection of two parents to create individuals for the next population. Some genetic operators like mutation and crossover are also utilized in this step for production of new population. These processes will be iterated until stopping criterion is met.

\section{APPLICATION OF WELDING OPTIMIZATION PROCEDURE}

$\mathrm{I}$ $\mathrm{n}$ this section, tensile strength of welded AA2024, also, tensile strength, and ultimate strength of welded AA5050 are optimized by GA-RSM. In this regard, at first, output parameters for all design points are determined with Design of Experiments. Then, relationship between the output parameters and the independent variables is predicted by response function. In this paper, the Latin Hypercube Sampling Design (LHSD) technique has been applied for selecting a set of data points. The LHSD method is an advanced form of the Monte Carlo sampling that avoids clustering samples. In addition, the third order polynomial is employed as a function of response surface. 


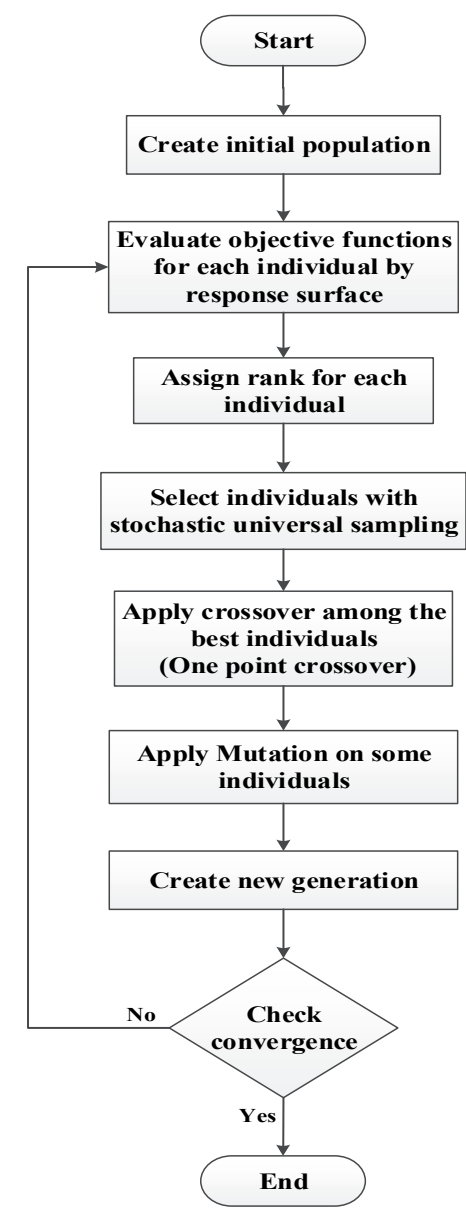

Figure 3: Flowchart of hybrid optimization methodology based on combination of Genetic Algorithm and Response Surface Methodology (GA-RSM).

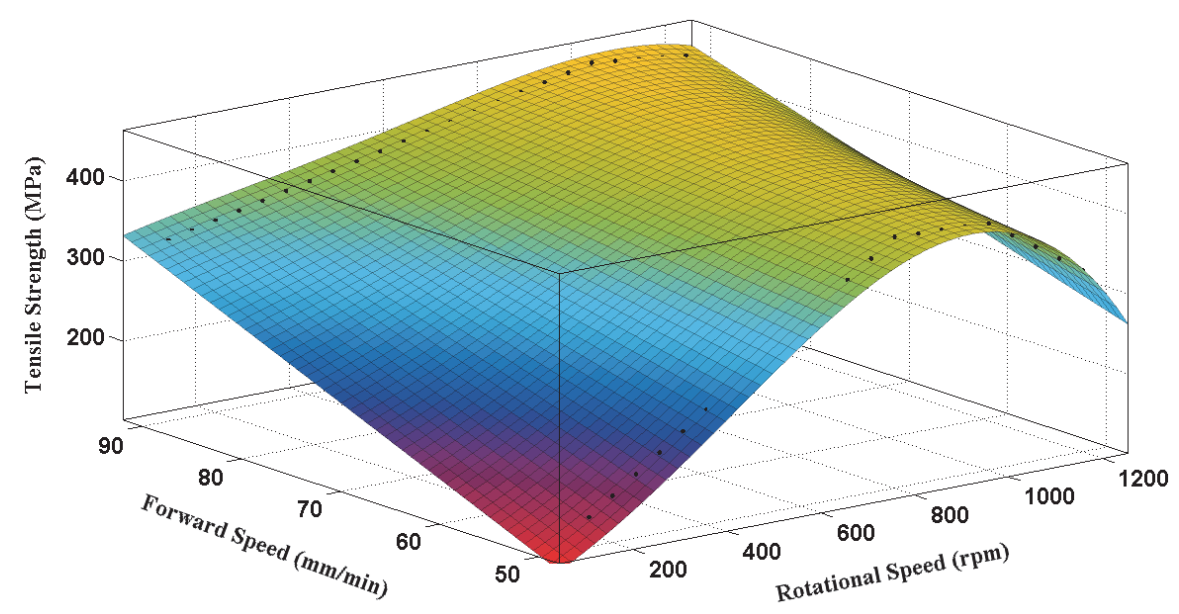

Figure 4: Effects of forward and rotational speed on tensile strength of AA2024 using RSM.

From literature and previous researches [21], in this study among many independent variables, forward and rotational speed have been selected as most influential parameters (independent variables). Tensile strength was considered as objective function for AA2024 and tensile and ultimate strength were considered as objective functions for AA5050. Lower and upper band of forward speed for both AA2024 and AA5050 are assumed as 25 and $95 \mathrm{~mm} / \mathrm{min}$, respectively. In addition, lower and upper band of rotational speed for both AA2024 and AA5050 are considered as 100 and $1300 \mathrm{rpm}$, respectively. Mentioned parameters could be varied between lower and upper band continuously. It will be proven that 
employing GA-RSM reduces the number of required experimental tests to find optimum point and acceptable optimum region, significantly. Figs. 4 and 5 illustrate three dimensional response surface plots for the tensile strength of AA2024 and AA5050, respectively. Three dimensional response surface plot for the ultimate strength of AA5050 has been shown in Fig. 6.

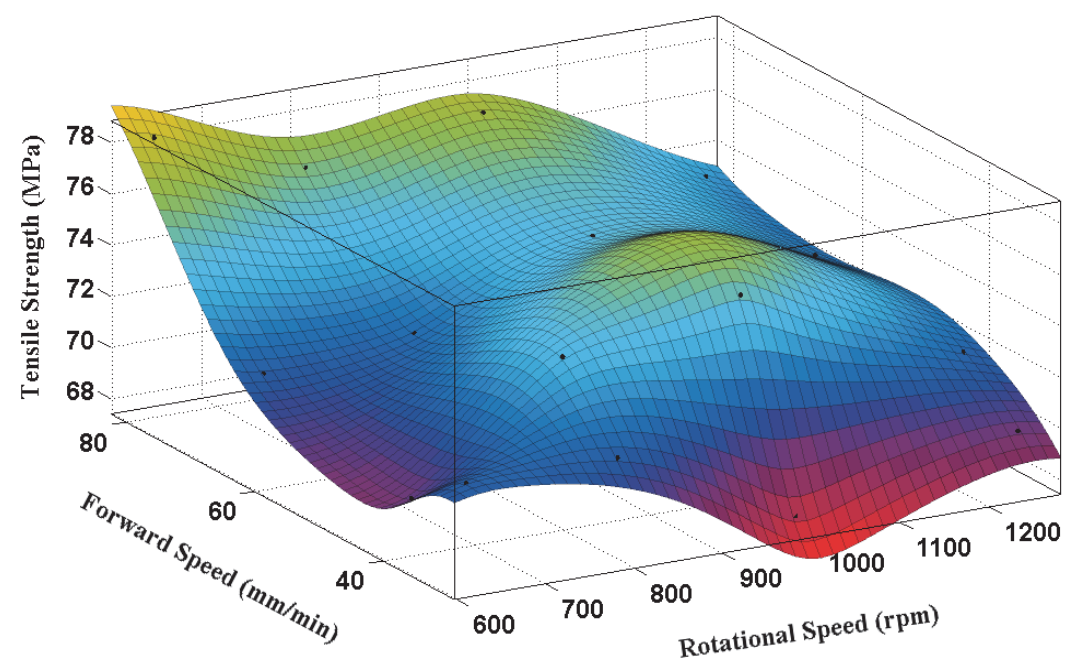

Figure 5: Effects of forward and rotational speed on the tensile strength of AA5050 using RSM.

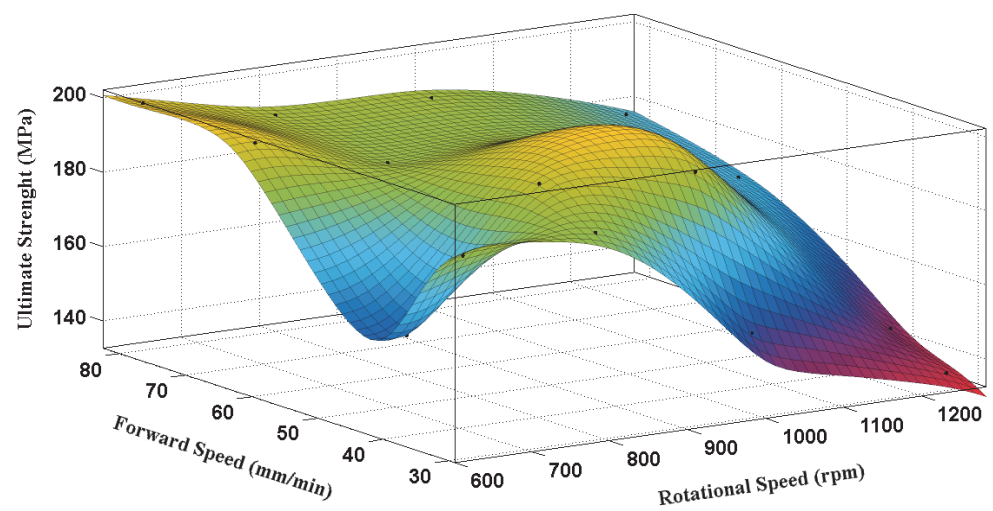

Figure 6: Effects of forward and rotational speed on ultimate strength of AA5050 using RSM.

Three dimensional response surface plots clearly show the effect of independent variables on output parameters.

\section{WELDING MODALITY SURVEY}

$\Lambda$ $\mathrm{s}$ it previously mentioned, the rotation and forward speed of tool are two significant parameters that can effect on final state of welding quality [21]. The aforementioned parameters effect on the amount of heat transferring in weld region. Therefore, un-controlled tool speed can create defects such as cavity and flaw [18]. Tensile and ultimate strength of welded AA2024 and AA5050 are assumed for optimization with GA-RSM.

In the present research, various tool speeds were investigated around GA-RSM's optimum suggested points on both AA2024 and AA5050. Fig. 7 represents weld region of AA2024 and AA5050 for different rotation and forward speeds.

As Fig. 4 shows, different welding region quality has been achieved in various rotation and forward speeds. For more detail investigation of welding surface quality, microstructural metallography was performed. In this regard, specimens were pre-pared by cutting up Aluminum sheet in transverse direction of weld-line and were polished by both sandpaper 
carbide (up to grade 5000) and Alumina powder. Furthermore, etching process performed by modified POLTON solution for $45 \mathrm{~s}$.

Tunnel and groove defects are visible in specimens due to inadequacy in rotation and forward speed. Microstructural metallography can show the tunnel and groove defects in specimens (Fig. 8) in un-optimized rotation and forward speeds.

AA2024

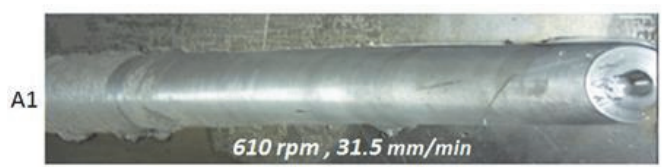

B1

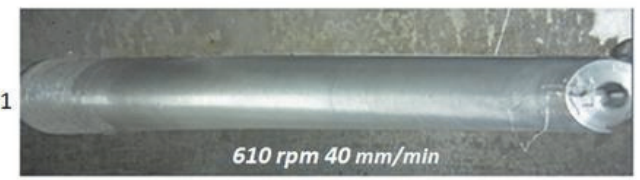

C1
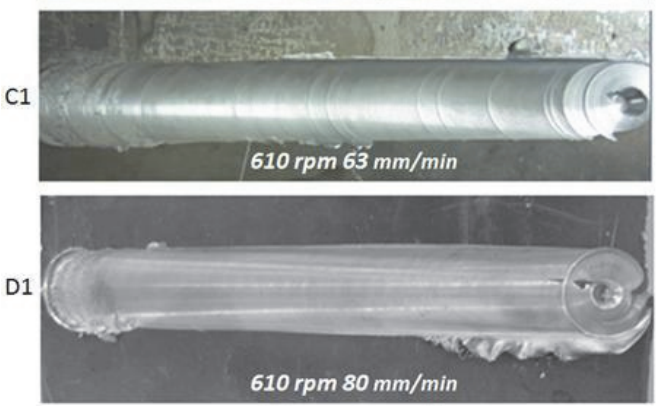

11

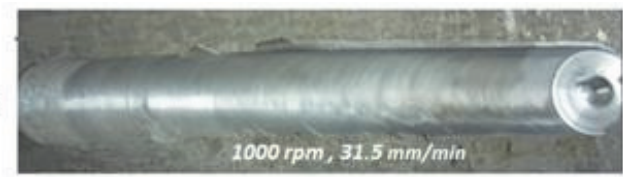

11
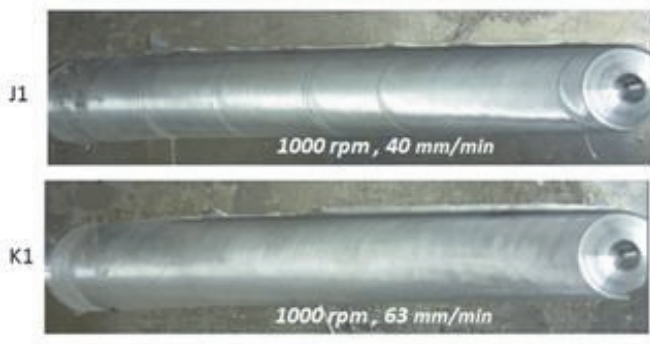

L1

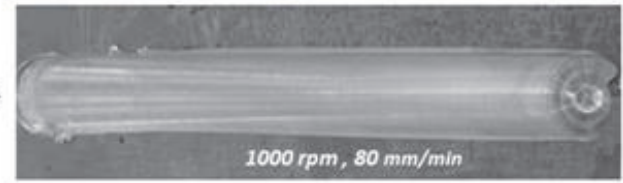

AA5050

E1

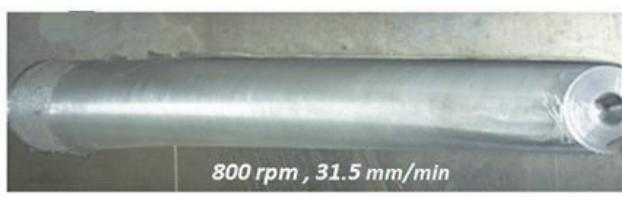

F1

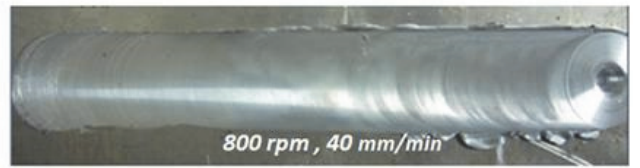

G1

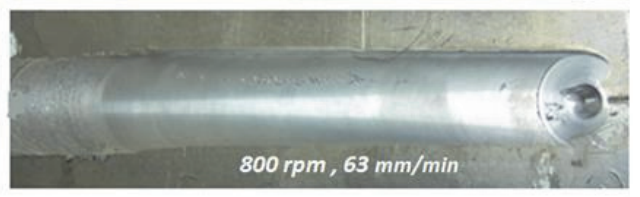

$\mathrm{H} 1$
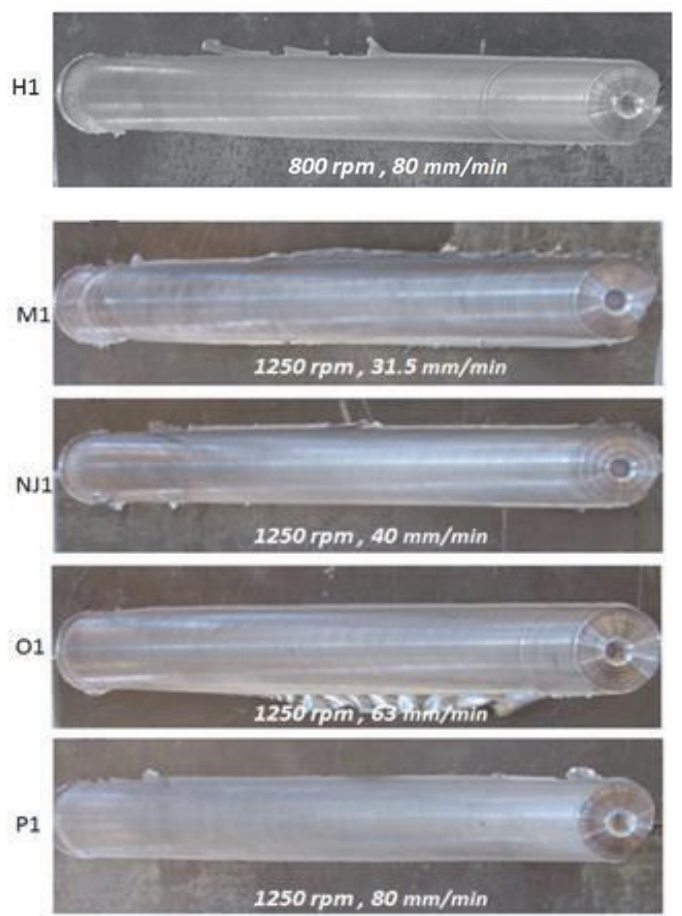

Figure 7: Welded specimens in different rotation and forward speeds.

As mentioned before, welded region usually consists of three different regions i.e. Stir Zone (SZ), Heat Affected Zone (HAZ) and Thermo Mechanically Affected Zone (TMAZ). In the stirring zone as compared to the base metal, grains are extremely fine and homogeneous. This phenomenon is caused by recrystallization followed by severe plastic deformation that has occurred in this region. TMAZ appears between the SZ and the HAZ region. In addition, grains are similar to cold forming processes that has squeezed longitudinally in a particular direction. Fig. 9 (a) and 6 (b) represent the 2024 and 5050 Aluminum alloy microstructural grain at the center of stir zone. 

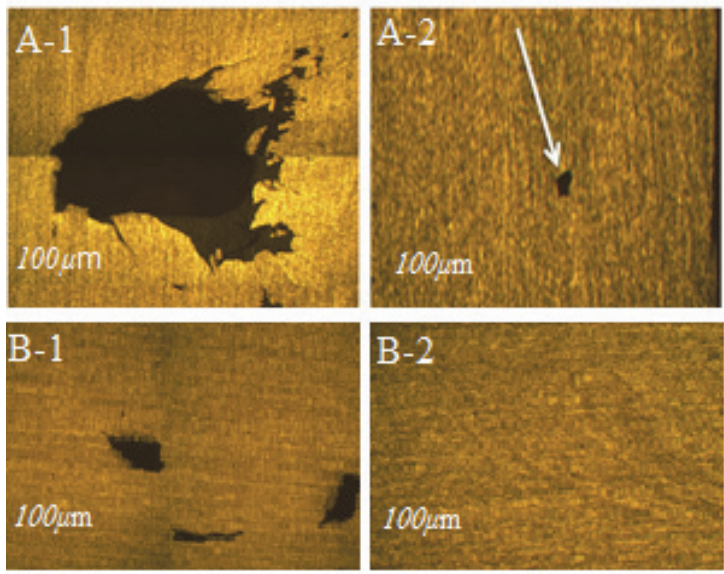

Figure 8: (A-1, A-2) and (B-1, B-2) represent cavity and tunnel defects for AA2024 and AA5050 specimens, respectively.

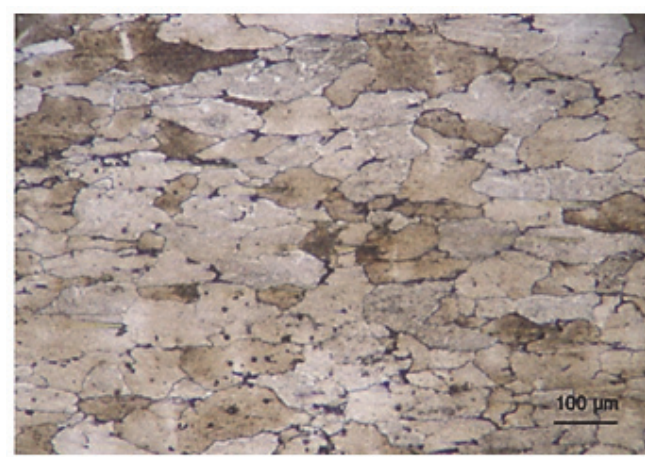

(a)

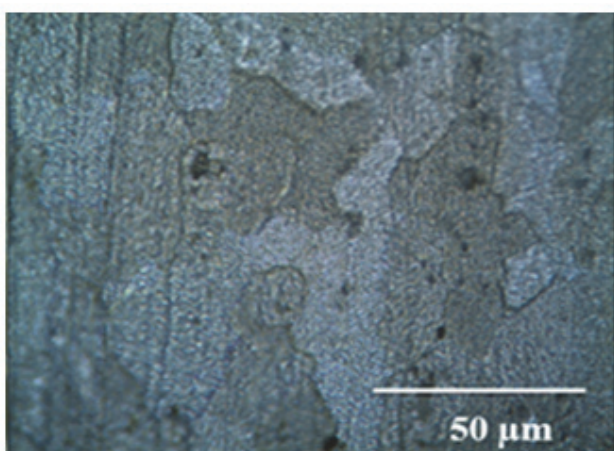

(b)

Figure 9: (a) and (b) 2024 and 5050 Aluminum alloy microstructural grain at the center of SZ.

\section{MECHANICAL PROPERTIES OF WELDED JOINTS}

7 ake into account of strength detection of welding, tensile and hardness tests were investigated. For this purpose, tensile test specimens prepared according to the ASTME8 (see Fig. 10 (a)). Also, Vickers test was selected as

Hardness test (see Fig. 10 (b)). In this regard, load of $100 \mathrm{gr}$ in 15 seconds dropped at the welded region and for that, $5.1 \mathrm{~mm}$ deformation was measured.

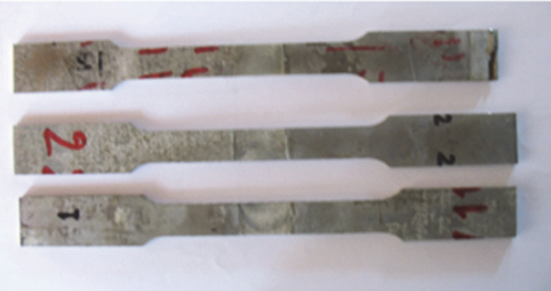

(a)

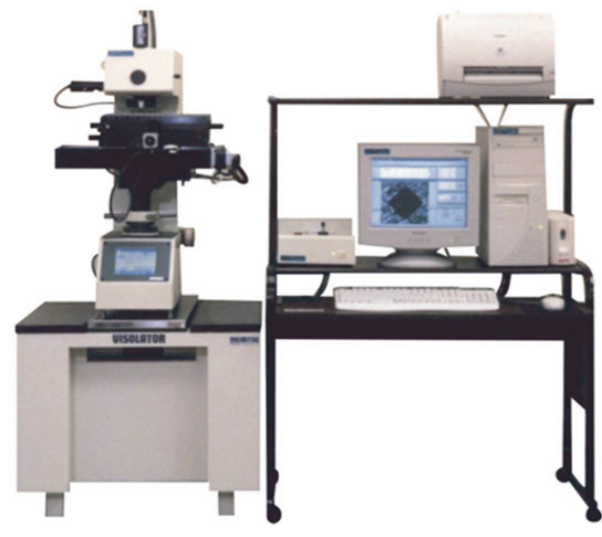

(b)

Figure 10: (a) Tension specimens according to ASTM E8 (b) Vickers test. 
Yield strength, ultimate strength, fracture zone, forward and rotational speed results of welded specimens for both AA5050 and AA2024 are evaluated experimentally. The results are listed in Tab. 3 and Tab. 4 for AA 5050 and AA 2024 respectively.

\begin{tabular}{|c|c|c|c|c|c|c|}
\hline $\begin{array}{l}\text { Specimen } \\
\text { name }\end{array}$ & Fracture zone & Elongation $\%$ & $\begin{array}{l}\text { Yield strength } \\
(\mathrm{MPa})\end{array}$ & $\begin{array}{c}\text { ultimate } \\
\text { strength } \\
(\mathrm{MPa})\end{array}$ & Forward speed & $\begin{array}{l}\text { Rotational } \\
\text { Speed (rpm) }\end{array}$ \\
\hline A & $\mathrm{NZ}$ & 23.25 & 71.43 & 185.71 & 31.5 & 630 \\
\hline B & $\mathrm{NZ}$ & 11.5 & 69.68 & 159.34 & 40 & 630 \\
\hline C & HAZ & 31.81 & 71.43 & 197.80 & 63 & 630 \\
\hline $\mathrm{D}$ & $\mathrm{BM}$ & 34.21 & 78.32 & 198.65 & 80 & 630 \\
\hline $\mathrm{E}$ & NZ & 23.91 & 71.40 & 186.81 & 31.5 & 800 \\
\hline $\mathrm{F}$ & TMAZ & 28.71 & 74.18 & 195.05 & 40 & 800 \\
\hline G & $\mathrm{NZ}$ & 25.12 & 71.98 & 187.41 & 63 & 800 \\
\hline $\mathrm{H}$ & $\mathrm{NZ}$ & 25.85 & 76.14 & 190.42 & 80 & 800 \\
\hline I & $\mathrm{NZ}$ & 10.7 & 67.93 & 153.85 & 31.5 & 1000 \\
\hline $\mathrm{J}$ & TMAZ & 27.56 & 75.4 & 192.3 & 40 & 1000 \\
\hline K & $\mathrm{NZ}$ & 25.63 & 74.58 & 187.91 & 63 & 1000 \\
\hline $\mathrm{L}$ & TMAZ & 26.05 & 77.08 & 189.06 & 80 & 1000 \\
\hline M & $\mathrm{NZ}$ & 7.07 & 69.75 & 135.54 & 31.5 & 1250 \\
\hline $\mathrm{N}$ & $\mathrm{NZ}$ & 9.63 & 71.66 & 142.54 & 40 & 1250 \\
\hline $\mathrm{O}$ & $\mathrm{NZ}$ & 15.93 & 72.32 & 170.06 & 63 & 1250 \\
\hline $\mathrm{P}$ & $\mathrm{NZ}$ & 18.02 & 73.08 & 177.07 & 80 & 1250 \\
\hline Base metal & & 25.1 & 110.85 & 210 & & \\
\hline
\end{tabular}

Table 3: Experimental evaluation and tool speed of AA 5050.

\begin{tabular}{cccccc}
\hline Specimen name & Fracture zone & Elongation $\%$ & $\begin{array}{c}\text { Yield strength } \\
\text { for } 50 \mathrm{~mm} / \mathrm{min} \\
\text { forward speed } \\
(\mathrm{MPa})\end{array}$ & $\begin{array}{c}\text { Ultimate strength } \\
\text { in } 90 \mathrm{~mm} / \mathrm{min} \\
\text { forward speed } \\
(\mathrm{MPa})\end{array}$ & $\begin{array}{c}\text { Rotational speed } \\
\text { (rpm) }\end{array}$ \\
A & NZ & 12 & 266.4 & 373.8 & 450 \\
B & NZ & 13 & 287.6 & 380.4 & 500 \\
C & HAZ & 12.4 & 308.8 & 387 & 550 \\
D & BM & 12.1 & 330 & 393.6 & 600 \\
E & NZ & 11.8 & 351.2 & 400.2 & 650 \\
F & TMAZ & 11.2 & 372.4 & 406.8 & 700 \\
G & NZ & 11 & 393.6 & 413.4 & 750 \\
H & NZ & 13.2 & 414.8 & 420 & 800 \\
I & NZ & 14.7 & 413.35 & 426.6 & 850 \\
J & TMAZ & 15.2 & 411.9 & 433.2 & 900 \\
K & NZ & 18.4 & 410.45 & 439.8 & 950 \\
L & TMAZ & 20.8 & 409 & 446.3 & 1000 \\
M & NZ & 17.8 & 388.77 & 442.9 & 1050 \\
N & NZ & 15.5 & 368.54 & 439.5 & 1100 \\
O & NZ & 11.9 & 348.31 & 436.1 & 1150 \\
P & NZ & 8.4 & 328.1 & 432.7 & 1200 \\
Base metal & & 210 & & & \\
\hline
\end{tabular}

Table 4: Experimental evaluation and tool speed of AA 2024. 
As it shown in Tab. 3 and Tab. 4, the highest tensile strength for AA2024 and AA5050 reported as 446.3 (MPa) and $198.65(\mathrm{MPa})$ at the 1000 and 630 rotational speeds (rpm), respectively. Furthermore, Fig. 11 indicates the fracture region of AA2024 and AA5050 specimens. As it can be found, initiation and propagation of crack in welded specimens begin from the TMAZ and SZ regions.
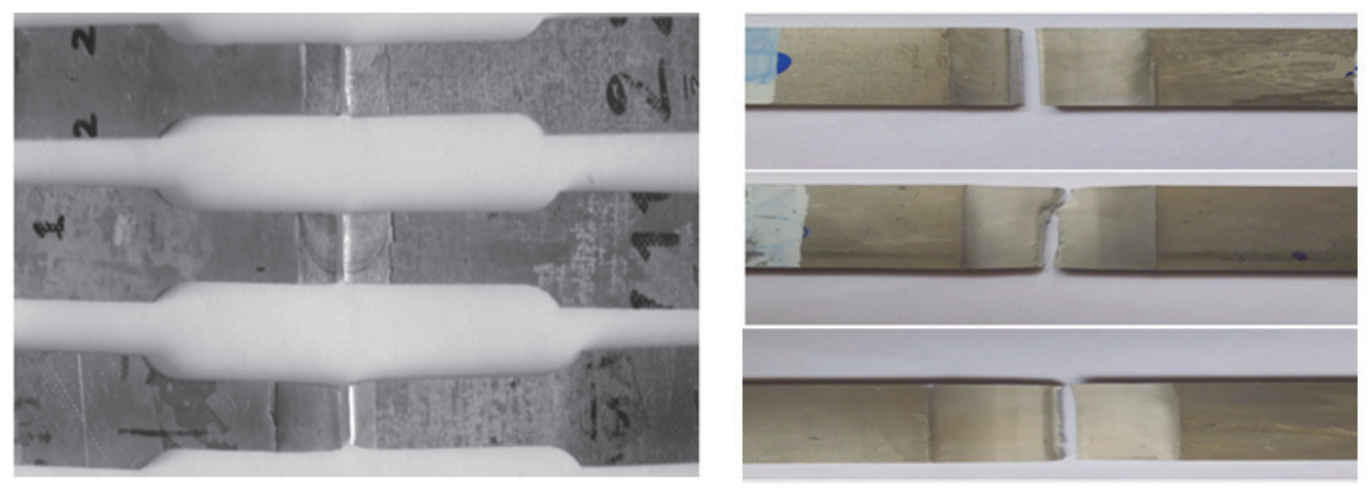

Figure 11: Fracture region of AA2024 and AA5050 specimens.

\section{RESULTS AND DISCUSSION}

T $\mathrm{n}$ this study, presented hybrid optimization algorithm (GA-RSM) reduces the number of required experimental tests to find optimum point and acceptable optimum region, significantly. Optimum region is an area which contains optimum point. On the other hand, experimental tests around the optimum points (or optimum region) confirmed the results of optimization processes (Fig. 12).

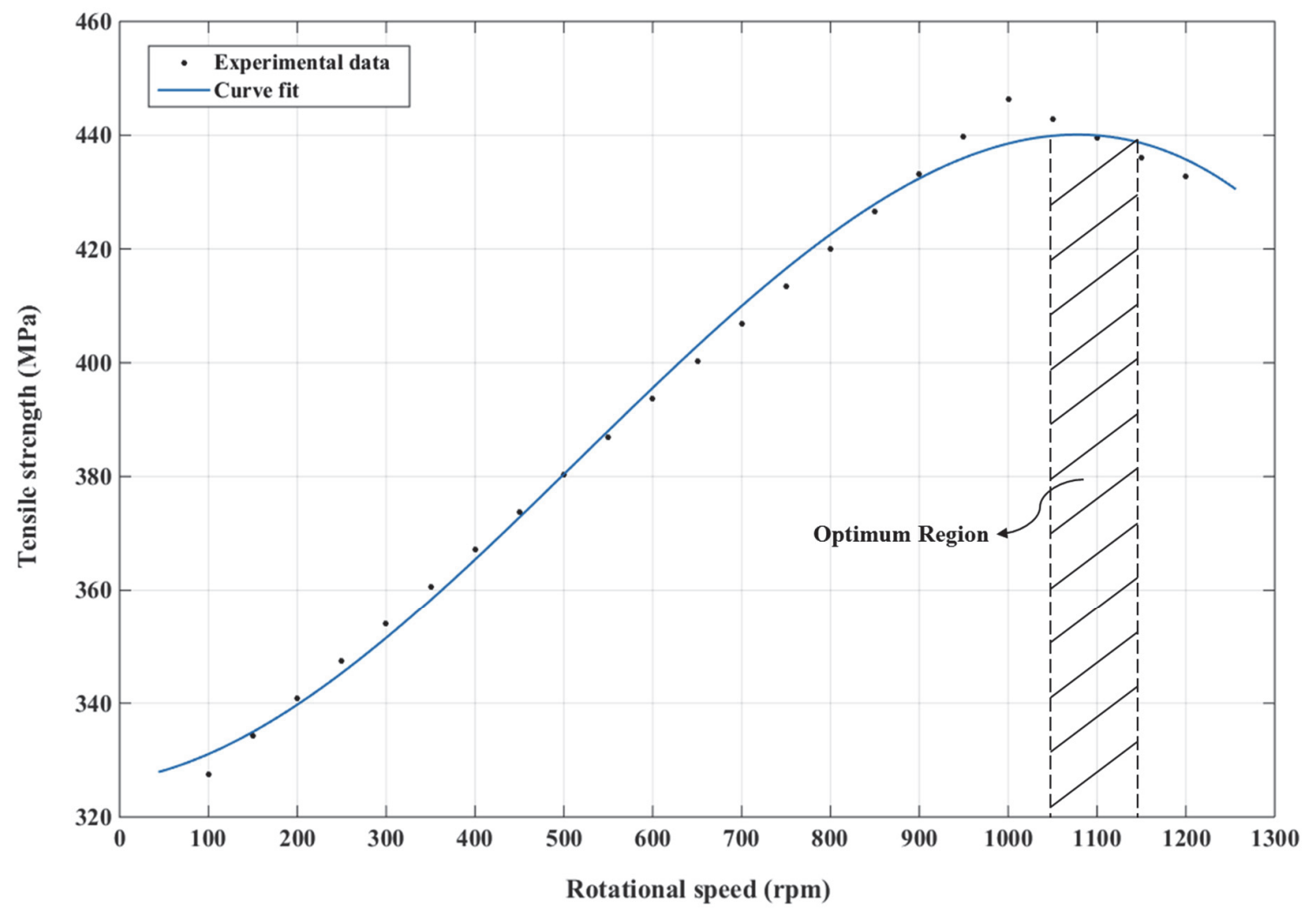

Figure 12: Optimum domain of tensile strength versus rotational speed. 
Furthermore, Coefficient (Eq. 8) has been calculated for validation of model's goodness. The parameter indicates matching of experimental and predicted values data based on the response surface method. Figs. 13 and 14 represent the parameter for AA2024 and AA5050 welded specimens, respectively.

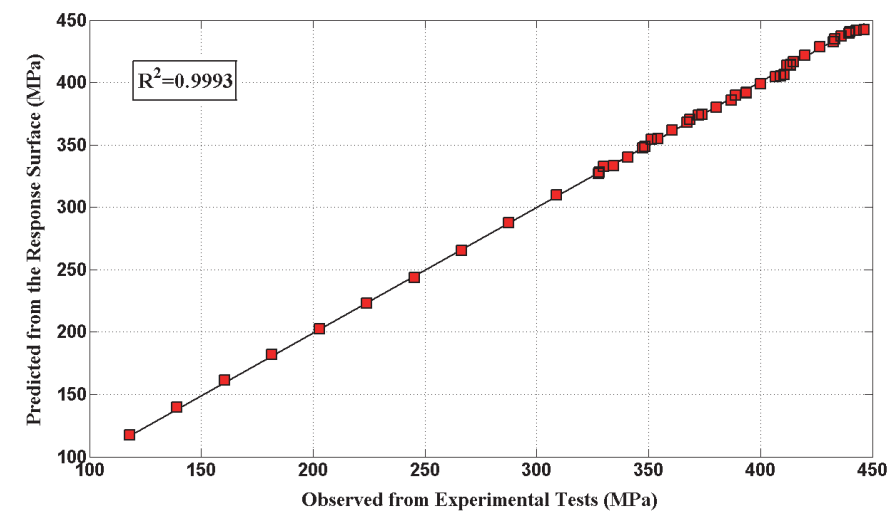

Figure 13: $\mathrm{R}^{2}$ parameter for AA2024 based on RSM of tensile strength.

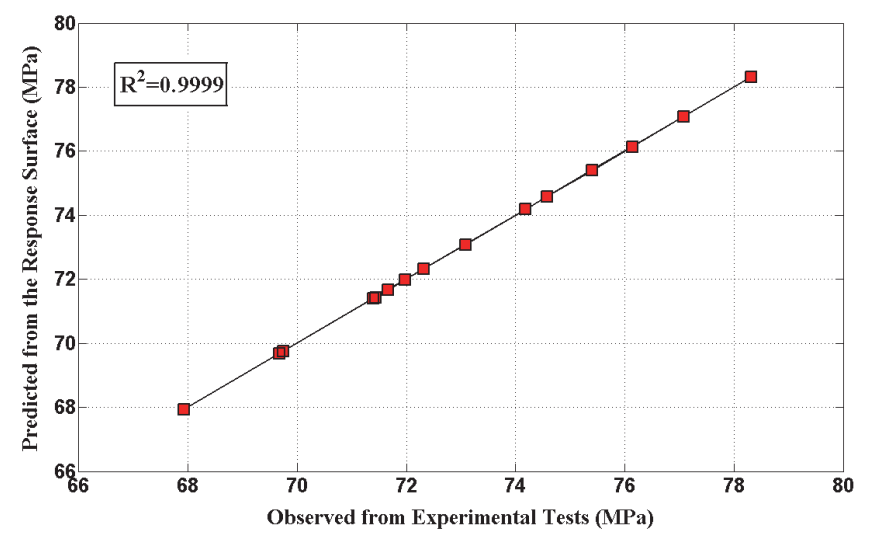

Figure 14: $\mathrm{R}^{2}$ parameter for AA5050 based on RSM of tensile strength.

In addition, $\mathrm{R}^{2}$ parameter is evaluated for ultimate strength of AA5050 in Fig.15.

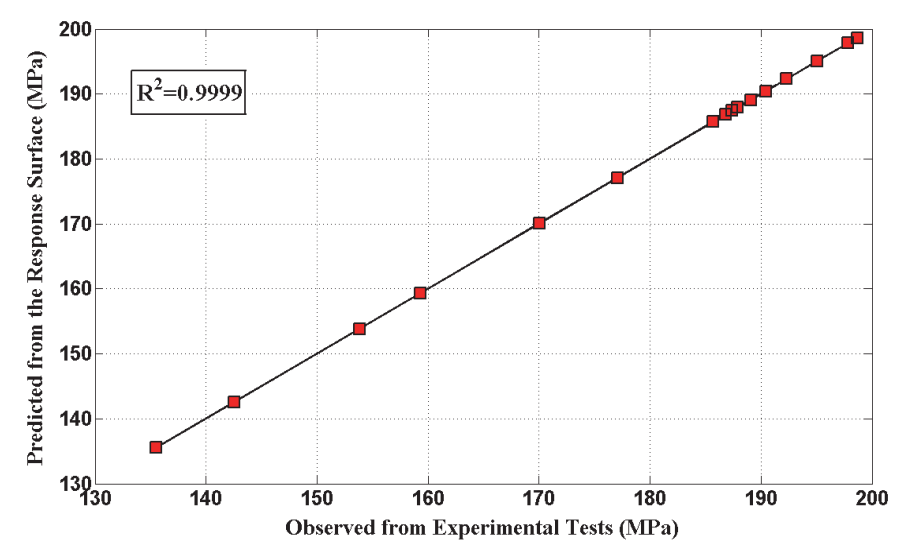

Figure 15: $\mathrm{R}^{2}$ parameter for AA5050 based on RSM of ultimate strength.

As it shown in Fig's. 13-15, $\mathrm{R}^{2}$ is approximated to $1(\approx 1)$. It means that, there is an adequate agreement between predicted values of the RSM and experimental data. Moreover, for optimization the GA parameters such as elitist choice, mutation and crossover probability and convergence stability percentage were considered as $3 \%, 2 \%, 50 \%$, and $0.01 \%$. In addition, in order to obtain the best answer for objective function, three initial populations of GA were evaluated as 50, 75 and 100. 
Each initial population is created during a random process. The results of GA optimization for three different initial populations are presented in Tab. 5, Tab. 6 and Tab. 7. The aforementioned Tables are indicating that there are insignificant differences between the results for three different initial populations.

\begin{tabular}{cccc}
\hline Initial Population & $\begin{array}{c}\text { Rotational Speed } \\
(\mathrm{Rpm})\end{array}$ & $\begin{array}{c}\text { Forward Speed } \\
(\mathrm{Mm} / \mathrm{Min})\end{array}$ & $\begin{array}{c}\text { tensile strength } \\
(\mathrm{MPa})\end{array}$ \\
50 & 1104.2 & 94.338 & 461.01 \\
75 & 1096.8 & 94.573 & 462.23 \\
100 & 1107.8 & 94.651 & 462.52 \\
\hline
\end{tabular}

Table 5: GA optimization of AA2024 for different initial populations.

\begin{tabular}{cccc}
\hline Initial Population & $\begin{array}{c}\text { Rotational Speed } \\
(\mathrm{Rpm})\end{array}$ & $\begin{array}{c}\text { Forward Speed } \\
(\mathrm{Mm} / \mathrm{Min})\end{array}$ & $\begin{array}{c}\text { tensile strength } \\
(\mathrm{MPa})\end{array}$ \\
50 & 512.29 & 87.903 & 80.455 \\
75 & 481.05 & 85.475 & 80.48 \\
100 & 499.58 & 85.074 & 80.492 \\
\hline
\end{tabular}

Table 6: GA optimization of AA5050 for different initial populations.

\begin{tabular}{cccc}
\hline Initial Population & $\begin{array}{c}\text { Rotational Speed } \\
(\mathrm{Rpm})\end{array}$ & $\begin{array}{c}\text { Forward Speed } \\
(\mathrm{Mm} / \mathrm{Min})\end{array}$ & $\begin{array}{c}\text { ultimate strength } \\
(\mathrm{MPa})\end{array}$ \\
50 & 466.9 & 72.725 & 216.33 \\
75 & 509.12 & 71.087 & 217.36 \\
100 & 490.87 & 70.296 & 217.56 \\
\hline
\end{tabular}

Table 7: GA optimization of AA5050 for different initial populations.

Furthermore, tensile and ultimate strength as an objective function versus number of evaluations for three different initial populations have been demonstrated as well in Fig. 16 to Fig. 18.

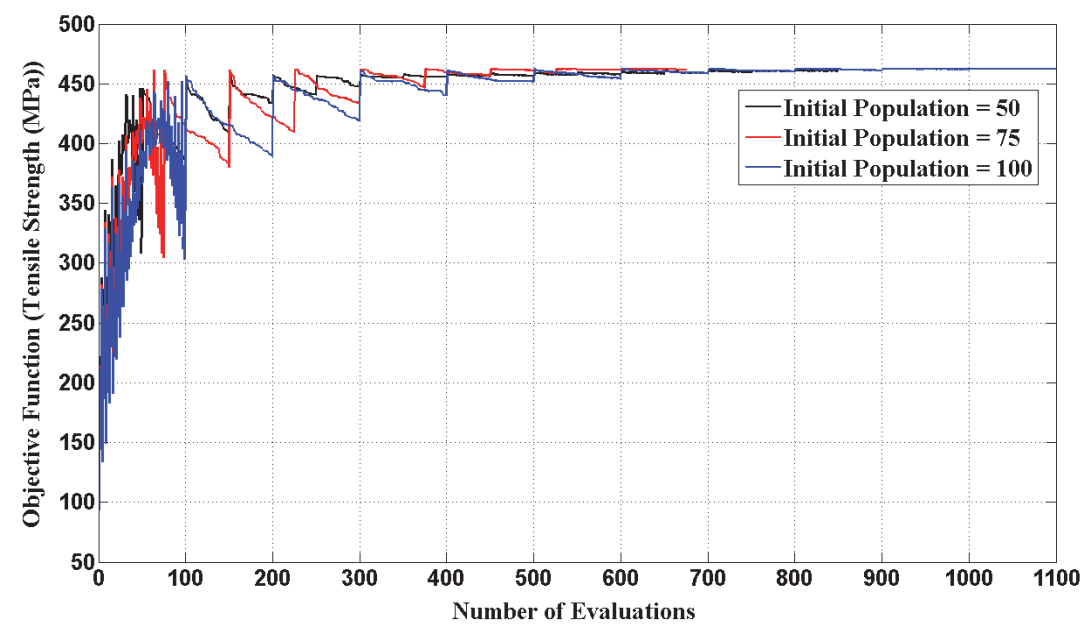

Figure 16: Tensile strength of AA2024 versus number of evaluations for three different initial populations.

As it shown in Figs. 15 to 17, for all three distinct initial populations, tensile strength data for AA2024 and AA5050 obtained approximately as 462 and $80.5 \mathrm{MPa}$ respectively. In addition, the evaluation reported for ultimate strength of AA5050 is $217 \mathrm{MPa}$. In the following, convergence stability versus the number of generations for three initial populations has been investigated (see Fig. 19 and Fig. 20). The convergence stability criterion is based on mean and standard deviation of the output parameters. It means that, for stable population, the optimization is converged. 


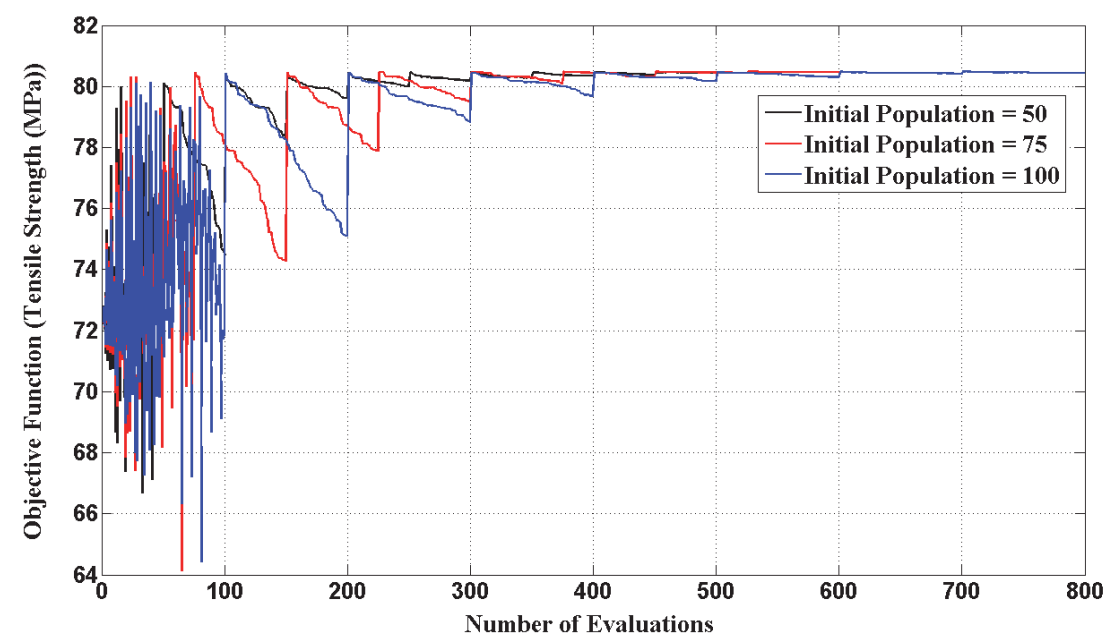

Figure 17: Tensile strength of AA5050 versus number of evaluations for three different initial populations.

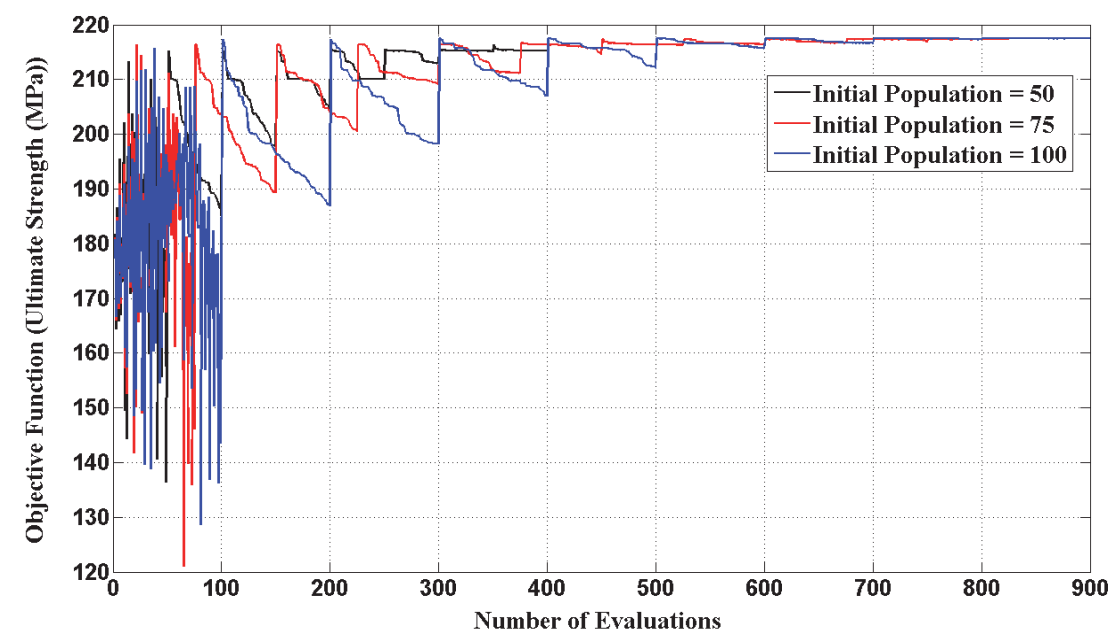

Figure 18: Ultimate strength of AA5050 versus number of evaluations for three different initial populations.

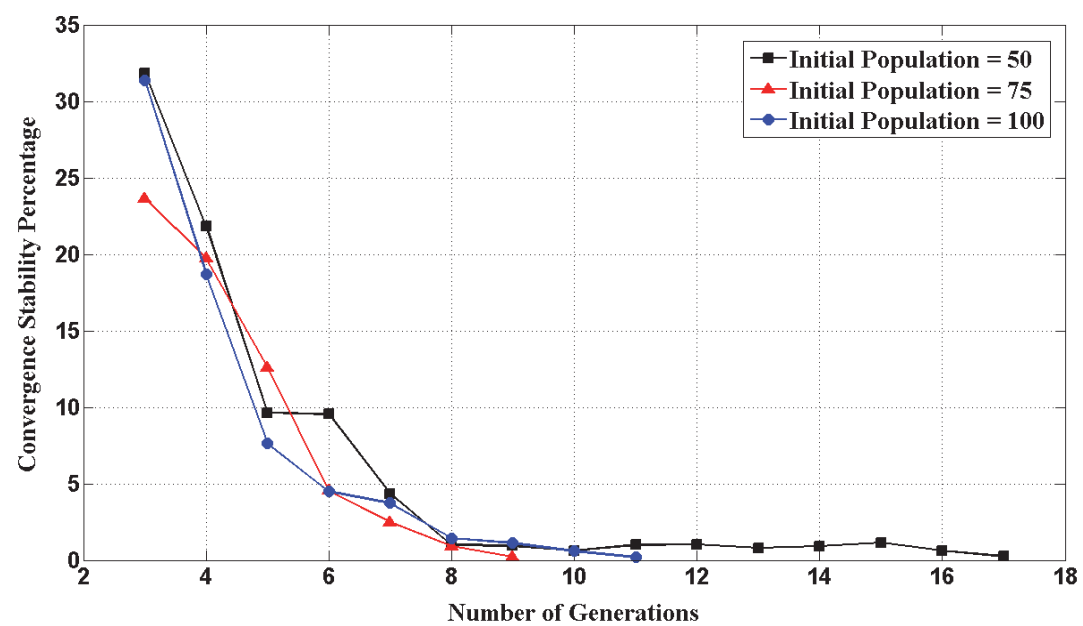

Figure 19: Convergence stability of AA2024 versus number of generations for three different initial populations. 


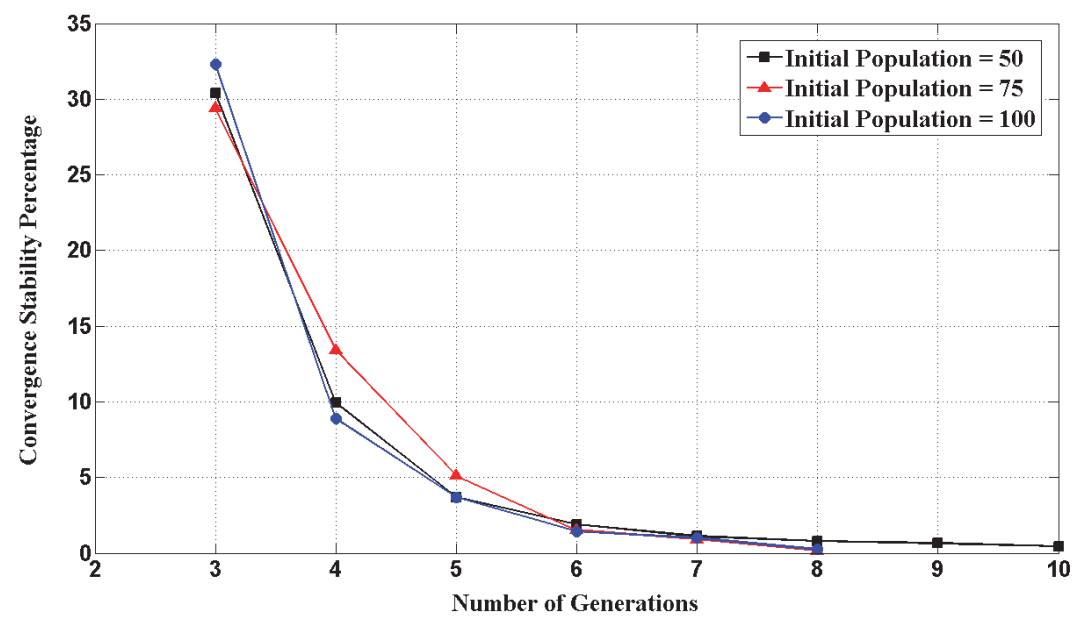

Figure 20: Convergence stability of AA5050 versus number of generations for three different initial populations.

It could be found that GA in combination with RSM has been converged after $17^{\text {th }}, 9^{\text {th }}$ and $11^{\text {th }}$ generations for 50,75 and 100 initial population, respectively. Therefore, GA has been converged promptly with 75 and 100 initial populations for AA2024 and AA5050 in comparison with other populations, respectively.

\section{CONCLUSIONS}

A n optimized Friction Stir Welding (FSW) process has been investigated in this research. Critical mechanical properties of welded zone such as yield and ultimate strength of two kinds of Aluminum alloys are targeted. Tool's rotational and forward speed are recognized as more effective parameters in FSW procedure on the mechanical properties of welded region. A hybrid optimization methodology based on both Genetic Algorithm (GA) and the Response Surface Methodology (RSM) named here as GA-RSM was proposed for approximation of the crucial tool's rotational and forward speed. In the aforementioned tool's speeds, maximum tensile and ultimate strength of welded zone could be achieved. In this regard, experimental tests were performed on two useful Aluminum alloys, i.e. AA2024 and AA5050. The results show that by employing the new presented hybrid optimization approach, more accuracy and reliability obtained for various tool's speed in comparison to other techniques.

\section{REFERENCES}

[1] Habibnia, M., Shakeri, M., Nourouzi, S. and Karimi, N., (2012). Effect of tool rotation speed and feed rate on friction stir welding of 1100 aluminum alloy to carbon steel. In Advanced Materials Research (Vol. 445, pp. 741-746). Trans Tech Publications. DOI: 10.4028/www.scientific.net/AMR.445.741.

[2] Uzun, H., Dalle Donne, C., Argagnotto, A., Ghidini, T. and Gambaro, C., (2005). Friction stir welding of dissimilar Al 6013-T4 to X5CrNi18-10 stainless steel. Materials \& design, 26(1), pp.41-46. DOI: 10.1016/j.matdes.2004.04.002.

[3] Lee, W.B., Schmuecker, M., Mercardo, U.A., Biallas, G. and Jung, S.B., (2006). Interfacial reaction in steel-aluminum joints made by friction stir welding. Scripta Materialia, 55(4), pp.355-358. DOI: 10.1016/j.scriptamat.2006.04.028 .

[4] Zhu, X.K. and Chao, Y.J., (2004). Numerical simulation of transient temperature and residual stresses in friction stir welding of 304L stainless steel. Journal of materials processing technology, 146(2), pp.263-272. DOI: $10.1016 /$ j.jmatprotec.2003.10.025.

[5] Geiger, M., Micari, F., Merklein, M., Fratini, L., Contorno, D., Giera, A. and Staud, D., (2008). Friction Stir Knead Welding of steel aluminium butt joints. International Journal of Machine Tools and Manufacture, 48(5), pp.515-521. DOI: 10.1016/j.ijmachtools.2007.08.002.

[6] Jayaraj, R.K., Malarvizhi, S. and Balasubramanian, V., (2017). Electrochemical corrosion behaviour of stir zone of friction stir welded dissimilar joints of AA6061 aluminium-AZ31B magnesium alloys. Transactions of Nonferrous Metals Society of China, 27(10), pp.2181-2192. DOI: 10.1016/S1003-6326(17)60244-9. 
[7] Tanaka, T., Morishige, T. and Hirata, T., (2009). Comprehensive analysis of joint strength for dissimilar friction stir welds of mild steel to aluminum alloys. Scripta Materialia, 61(7), pp.756-759. DOI: 10.1016/j.scriptamat.2009.06.022.

[8] Fujii, H., Ueji, R., Morisada, Y. and Tanigawa, H., (2014). High strength and ductility of friction-stir-welded steel joints due to mechanically stabilized metastable austenite. Scripta Materialia, 70, pp.39-42. DOI: $10.1016 /$ j.scriptamat.2013.09.012.

[9] Watanabe, T., Takayama, H., Kimapong, K. and Hotta, N., (2003). Joining of steel to aluminum alloy by interfaceactivated adhesion welding. In Materials Science Forum, Trans Tech Publications, 426, pp. 4129-4134. DOI: $10.4028 / w w w . s c i e n t i f i c . n e t / M S F .426-432.4129$,

[10] Yong-Jai, K.W.O.N., Seong-Beom, S. and Dong-Hwan, P.A.R.K., (2009). Friction stir welding of 5052 aluminum alloy plates. Transactions of Nonferrous Metals Society of China, 19, pp. s23-s27. DOI: $10.1016 /$ S1003-6326(10)60239-7.

[11] Sharma, N. and Siddiquee, A.N., (2017). Friction stir welding of aluminum to copper-An overview. Transactions of Nonferrous Metals Society of China, 27(10), pp.2113-2136. DOI: 10.1016/S1003-6326(17)60238-3.

[12] Zhang, Q.Z., Gong, W.B. and Wei, L.I.U., 2015. Microstructure and mechanical properties of dissimilar Al-Cu joints by friction stir welding. Transactions of Nonferrous Metals Society of China, 25(6), pp.1779-1786. DOI: 10.1016/S1003-6326(15)63783-9

[13] Ilangovan, M., Boopathy, S.R. and Balasubramanian, V., (2015). Microstructure and tensile properties of friction stir welded dissimilar AA6061-AA5086 aluminium alloy joints. Transactions of Nonferrous Metals Society of China, 25(4), pp.1080-1090. DOI: 10.1016/S1003-6326(15)63701-3.

[14] Okuyucu, H., Kurt, A. and Arcaklioglu, E., (2007). Artificial neural network application to the friction stir welding of aluminum plates. Materials \& design, 28(1), pp.78-84. DOI: 10.1016/j.matdes.2005.06.003.

[15] Piccini, J.M. and Svoboda, H.G., (2017). Tool geometry optimization in friction stir spot welding of Al-steel joints. Journal of Manufacturing Processes, 26, pp.142-154. DOI: 10.1016/j.jmapro.2017.02.004.

[16] Shojaeefard, M.H., Khalkhali, A., Akbari, M. and Tahani, M., (2013). Application of Taguchi optimization technique in determining aluminum to brass friction stir welding parameters. Materials \& Design (1980-2015), 52, pp.587-592. DOI: $10.1016 /$ j.matdes.2013.06.003.

[17] Lakshminarayanan, A.K. and Balasubramanian, V., (2008). Process parameters optimization for friction stir welding of RDE-40 aluminium alloy using Taguchi technique. Transactions of Nonferrous Metals Society of China, 18(3), pp.548-554. 10.1016/S1003-6326(08)60096-5. DOI: 10.1016/S1003-6326(08)60096-5.

[18] De Vuyst, T., D’Alvise, L., Simar, A., De Meester, B. and Pierret, S., (2005). Finite element modelling of friction stir welding of aluminium alloy plates-inverse analysis using a genetic algorithm. Welding in the World, 49(3-4), pp.47-55. DOI: $10.1007 / \mathrm{BF} 03266475$

[19] Sankar, B.R. and Umamaheswarrao, P., (2017). Modelling and Optimisation of Friction Stir Welding on AA6061 Alloy. Materials Today: Proceedings, 4(8), pp.7448-7456. DOI: 10.1016/j.matpr.2017.07.076.

[20] Kumar, B.A. and Murugan, N., (2014). Optimization of friction stir welding process parameters to maximize tensile strength of stir cast AA6061-T6/AlNp composite. Materials \& Design, 57, pp.383-393. DOI: $10.1016 /$ j.matdes.2013.12.065.

[21] Qian, J., Li, J., Sun, F., Xiong, J., Zhang, F. and Lin, X., (2013). An analytical model to optimize rotation speed and travel speed of friction stir welding for defect-free joints. Scripta Materialia, 68(3-4), pp.175-178. DOI: $10.1016 /$ j.scriptamat.2012.10.008.

[22] Lakshminarayanan, A.K. and Balasubramanian, V., (2009). Comparison of RSM with ANN in predicting tensile strength of friction stir welded AA7039 aluminium alloy joints. Transactions of Nonferrous Metals Society of China, 19(1), pp.9-18. DOI: 10.1016/S1003-6326(08)60221-6.

[23] Jayaraman, M., Sivasubramanian, R., Balasubramanian, V. and Lakshminarayanan, A.K., (2008). Prediction of tensile strength of friction stir welded A356 cast aluminium alloy using response surface methodology and artificial neural network. Journal for Manufacturing Science and Production, 9(1-2), pp.45-60. DOI: 10.1515/IJMSP.2008.9.1-2.45.

[24] Legrand, X., Kelly, D., Crosky, A. and Crépin, D., (2006). Optimisation of fibre steering in composite laminates using a genetic algorithm. Composite structures, 75(1-4), pp.524-531. DOI: 10.1016/j.compstruct.2006.04.067.

[25] Bezerra, M.A., Santelli, R.E., Oliveira, E.P., Villar, L.S. and Escaleira, L.A., (2008). Response surface methodology (RSM) as a tool for optimization in analytical chemistry. Talanta, 76(5), pp.965-977.

DOI: $10.1016 /$ j.talanta.2008.05.019.

[26] Todoroki, A. and Ishikawa, T., (2004). Design of experiments for stacking sequence optimizations with genetic algorithm using response surface approximation. Composite structures, 64(3-4), pp.349-357.

DOI: $10.1016 /$ j.compstruct.2003.09.004. 


\section{NOMENClATURE}

b Unbiased estimator $\mathrm{b}$ of the coefficient vector $\beta$

F Quadratic polynomial function

X $n \times k$ Model matrix

$\mathrm{C}_{\mathrm{ij}} \quad$ Element of number $\mathrm{j}$ of variance covariance matrix

Y $n \times 1$ Vector of the observations

$\mathrm{R}^{2} \quad$ Adjusted coefficient of multiple determinations

Unknown coefficients

$\mathrm{x}_{\mathrm{i}} \quad$ Independent Variables

$\beta \quad k \times 1$ Vector of the regression coefficients

y $\quad$ Estimated Response

$\varepsilon \quad n \times 1$ vector of random errors

$\sigma \quad$ Error of $\mathrm{Y}$ 